\title{
Can we save the charismatic megaflora?
}

\author{
PETER CRANE
}

You don't have to look far to understand the importance of trees in our lives. They dominate vast swathes of the landscape and in many cultures provide the necessities of daily life. At the same time, their ubiquity makes it easy to take trees for granted. They have been exploited ruthlessly and our demand for agricultural land and raw materials means they are too often and too easily swept aside. Nevertheless, this seeming indifference belies the fact that human empathy for trees has deep roots, including strong emotional attachments and powerful cultural associations. The tree of the knowledge of good and evil in the Christian tradition and the Bodhi tree of Buddhism are just two examples. Regrettably, however, trees are under threat almost everywhere. This issue of Oryx is dedicated to reviewing diverse approaches to saving our charismatic megaflora and to raising awareness about their future.

In broad terms, we know that thousands of species of trees are threatened with extinction. For plants generally more than $20 \%$, perhaps 75,000 of a total of c. 380,000 species, are threatened (Kew, 2012). This preliminary estimate suggests that plants are less threatened than amphibians, more threatened than birds, and threatened to about the same degree as mammals. But more refined knowledge about the status of trees is harder to come by. One problem is the large number of species involved: 60,000-100,000 based on crude estimates (more than all species of amphibians, birds and mammals combined). Another is that because trees are not a discrete taxonomic group there is no cadre of specialists devoted to their systematics. Some plant families are composed entirely of trees, but in other groups trees are merely a subset.

But a list of tree species is only a beginning. We need to know more, especially about their geographical distribution, if we are to think strategically about tree conservation. Ideally we would go much further, to assess populations of each tree species and to understand the dynamics of the ecosystems of which they are part. We would also want to know the levels of threat faced by different species. In many parts of the world, however, simply listing all the species of trees and understanding their geographical distributions is beyond our grasp. The conservation status of more than four out of every five tree species remains to be assessed at even the most basic level (Newton et. al., 2015).

If assessing the conservation status of every tree species is an overwhelming prospect, turning that knowledge into

Peter Crane School of Forestry and Environmental Studies, Yale University, New Haven, USA. E-mail peter.crane@yale.edu conservation action is even more so. In the best of all possible worlds, populations of the most threatened species would be protected and monitored where they grow, and their ongoing survival would be incorporated into broader landscape, regional and national conservation plans. As a hedge against potential disaster in the wild, all threatened tree species would also be protected in ex situ collections, including in seed and germplasm banks. There is no technical reason why any plant species should go extinct ( $\mathrm{P}$. Smith, Botanic Gardens Conservation International, pers. comm.). In general, we know what needs to be done and how to do it. Scaling up the necessary action is a matter of resources, but it is also a matter of will and of the commitment of disparate stakeholders to work together more effectively.

If you like orderly and efficient problem solving, the world of plant conservation is not for you. There are a multitude of scientists, institutions, NGOs, and governments and their agencies, all with different agendas, priorities and interests. Top-down directives are hard to implement and problematic to coordinate. A shared sense of purpose, underpinned by unwavering commitment, is difficult to sustain. The Global Strategy for Plant Conservation has been a useful step, but collectively we still fall far short of the conservation action needed. In this messy and frustrating context, what is to be done?

The School of Forestry and Environmental Studies at Yale University was the brainchild of two progressive politicians of the early 2oth century, Theodore Roosevelt Jr and Gifford Pinchot. Roosevelt in particular was committed to action-not all of it well directed-but he got things done. In a matter of days, in early March 1907, Roosevelt and Pinchot working together created the 'midnight reserves': 16 million acres of new National Forests in the American West. At that particular political juncture opportunity and need for action came together. Roosevelt and Pinchot were not found wanting: they seized the moment.

Among the many memorable aphorisms of Roosevelt my favourite is 'Do what you can, with what you have, where you are.' This should be the rallying cry for all those interested in securing the future of trees. There is plenty to be done, there is no time to lose, and as opportunities arise they need to be seized with vigour. The Global Trees Campaign-a partnership between Fauna \& Flora International (of which Roosevelt was a member of the founding group) and Botanic Gardens Conservation International-sets out an overarching aspiration, but the only way to make more rapid progress is for every individual and every institution to find ways to amplify their impact. A bold vision is 
important, and coordination can work wonders where there are willing partners, but the work will be done from the bottom up, and every individual and institution has a role to play.

The sentiments of Roosevelt's call to action also connect with another useful rule of thumb: don't let the perfect be the enemy of the good. We should strive for the most scientifically defensible Red List of Trees. But at the same time, to guide our work and to provide data for action, we need a good, synonymized, working list of the conservation status of all tree species, and we need it urgently. Developing the perfect list is a Sisyphean task that will always elude us: the list will change as new knowledge accumulates. What is needed is a practical guide to help us decide how to act and in the best way. All the many different actors committed to working for the conservation of trees need to do what they can, in the best possible way, in the circumstances in which they find themselves, with the resources at their disposal.

If it was Roosevelt, as President, who with his signature brought 16 million acres into the U.S. National Forest, Pinchot made an equally lasting contribution by providing the funds to create a School of Forestry at Yale. The goal was to help train managers for the lands and forests of the recently created U.S. Forest Service. Pinchot's young foresters did excellent work, often in difficult circumstances. But the impact over time has been more profound. Aldo Leopold was one notable product of Pinchot's vision, but since the school was founded thousands of others have also made a difference, each in their own way. Pinchot took the long view and understood the importance of investing in people. The lesson for the future of trees is simple. There is little that is more important than building human capacity and giving people the tools they need to help manage the world's trees.

A great irony of the 21st century is that we live in an increasingly interconnected world but one that remains stubbornly fragmented. Nearly 200 countries find it hard to agree how to address even the most urgent issues that threaten the future of humanity and the planet. The landscape of potential actors who could contribute to the conservation of trees is similarly fragmented, and where there was once a more or less integrated plant science there are now systematists, ecologists, agronomists, foresters, physiologists, geneticists and others, all operating increasingly independently. Civil society has developed similarly. NGOs have proliferated and governments at every level are vastly complex. The people who know the species, ecosystems, stakeholders, regulatory environment, policy makers and funders are scattered and too often isolated. It is an illusion to believe they can be brought together around a tightly focused, topdown, common agenda to save trees. But it is not an illusion to think that under the umbrella of the Global Trees Campaign, through the efforts of individuals and institutions that are prepared to reach out and work creatively with others, we can fulfil our ethical responsibilities for stewardship more effectively.

So can we save the charismatic megaflora? With the world changing before our eyes it is easy to despair and, frustratingly, species conservation is out of fashion except where it is focused on the charismatic megafauna. New service-based ideas, mainly positioned around what we can take from nature or, more abstractly, what nature does for us, are ever more prominent (Scales, 2015). Perhaps these arguments are the only ones that resonate with some audiences, but against the multi-generational majesty of longlived trees they betray a depressingly utilitarian view of the world. They also suggest that species are fungible, which they are not. We should not forget the individuality of species and the different contributions each has made and continues to make. We should also remember that for many people, in all cultures, ethical and moral arguments, as well as personal feelings about quality of life, often trump cold economics. There is more to the diversity of life than functional groups, no matter their heuristic value for modelling the way the world works. The great diversity of trees is important and we have a shared responsibility for its stewardship. To modify a line from another U.S. President that famously implored us to seek the higher ground: we should each ask not what nature can do for us, but what we can do for nature. The charismatic megaflora are a gift to the whole of humanity bequeathed to us by millions of years of evolution. It is important that we act now to ensure their future.

\section{References}

Kew (2012) Plants Under Pressure-A Global Assessment. The First Report of the Sampled Red Index List for Plants. Royal Botanic Gardens, Kew, UK. Http://www.kew.org/sites/default/files/ kppcont_027304.pdf [accessed 11 May 2015].

Newton, A., Oldfield, S., Rivers, M., Mark, J., Schatz, G., Garavito, N.T. et al. (2015) Towards a global tree assessment. Oryx, 49, 410-415.

Scales, I.R. (2015) Paying for nature: what every conservationist should know about political economy. Oryx, 49, 226-231. 